\title{
WDR1 Colocalizes With ADF and Actin in the Normal and Noise-Damaged Chick Cochlea
}

\author{
SEUNG-HA OH, ${ }^{1,2}$ HENRY J. ADLER, ${ }^{3}$ YEHOASH RAPHAEL ${ }^{1,2}$ AND \\ MARGARET I. LOMAX ${ }^{1 *}$ \\ ${ }^{1}$ Kresge Hearing Research Institute, Department of Otolaryngology-Head and Neck \\ Surgery; The University of Michigan Medical School, Ann Arbor, Michigan 48109-0506 \\ ${ }^{2}$ Department of Otolaryngology-Head and Neck Surgery, Seoul National University College \\ of Medicine, 110-744 Seoul, Korea \\ ${ }^{3} \mathrm{NIDCD} / \mathrm{NIH}$, Bethesda, Maryland 20892
}

\begin{abstract}
Auditory hair cells of birds, unlike hair cells in the mammalian organ of Corti, can regenerate following sound-induced loss. We have identified several genes that are upregulated following such an insult. One gene, WDR1, encodes the vertebrate homologue of actin-interacting protein 1 , which interacts with actin depolymerization factor (ADF) to enhance the rate of actin filament cleavage. We examined WDR1 expression in the developing, mature, and noise-damaged chick cochlea by in situ hybridization and immunocytochemistry. In the mature cochlea, WDR1 mRNA was detected in hair cells, homogene cells, and cuboidal cells, all of which contain high levels of F-actin. In the developing inner ear, WDR1 mRNA was detected in homogene cells and cuboidal cells by embryonic day 7 , in the undifferentiated sensory epithelium by day 9 , and in hair cells at embryonic day 16 . We also demonstrated colocalization of WDR1, ADF, and F-actin in all three cell types in the normal and noise-damaged cochlea. Immediately after acoustic overstimulation, WDR1 mRNA was seen in supporting cells. These cells contribute to the structural integrity of the basilar papilla, the maintenance of the ionic barrier at the reticular lamina, and the generation of new hair cells. These results indicate that one of the immediate responses of the supporting cell after noise exposure is to induce WDR1 gene expression and thus to increase the rate of actin filament turnover. These results suggest that WDR1 may play a role either in restoring cytoskeletal integrity in supporting cells or in a cell signaling pathway required for regeneration. J. Comp. Neurol. 448:399-409, 2002. @ 2002 Wiley-Liss, Inc.
\end{abstract}

Indexing terms: actin depolymerizing protein; cofilin; cytoskeleton; regeneration; actin dynamics

Acoustic overstimulation leads to sensory cell damage in the auditory epithelium. When hair cells degenerate in the organ of Corti, the mammalian auditory end-organ, they are replaced by nonsensory cells (supporting cells), resulting in an irreversible scar (Hawkins and Johnsson, 1976; Raphael and Altschuler, 1991b). In contrast, when hair cells are lost in the basilar papilla, the auditory sensory epithelium of birds, they are replaced by new hair cells. Immediately after sound overstimulation, the basilar papilla exhibits structural damage, including hair cell loss, alterations of the sensory surfaces of both surviving hair cells and supporting cells (SCs), and tectorial membrane destruction (Cotanche and Dopyera, 1990; Raphael and Altschuler, 1992; Saunders et al., 1992). Three to 4 days later, new hair cells appear in the damaged region
(Cotanche, 1987a; Corwin and Cotanche, 1988). Other inner ear tissues, including the tectorial membrane (Cotanche, 1987b; Cotanche, 1992) and the tegmentum vasculosum (Ryals et al., 1995), also undergo repair. This

Grant sponsor: NIH; Grant numbers: DC02492 and DC01634.

Dr. Oh is a scholar of the Korean Science and Engineering Foundation. *Correspondence to: Margaret I. Lomax, Kresge Hearing Research Institute, 9301E MSRBIII Box 0648, Ann Arbor, Michigan 48109-0648. E-mail: mlomax@umich.edu

Received 6 June 2001; Revised 7 January 2002; Accepted 26 March 2002 DOI 10.1002/cne.10265

Published online the week of May 20, 2002 in Wiley InterScience (www. interscience.wiley.com). 
structural repair results in the recovery of hearing thresholds (McFadden and Saunders, 1989; Adler et al., 1993; Niemiec et al., 1994), frequency selectivity (McFadden and Saunders, 1989), amplitude coding (Pugliano et al., 1993), and endocochlear potential (Poje et al., 1995). However, the molecular mechanisms underlying the morphologic and physiologic changes following noise damage are not well understood.

Our approach toward understanding the mechanisms of repair and regeneration in the chick cochlea has been to identify and characterize genes expressed in the injured chick cochlea following noise insult (Gong et al., 1996). The proteins encoded by these genes may be involved in the process of repair or the production of new hair cells. One of these genes, WDR1, encodes WD40 repeat protein 1 (WDR1; Adler et al., 1999), the vertebrate homologue of actin-interacting protein 1 (AIP1) (Amberg et al., 1995). Recently, Xenopus AIP1 was isolated in a yeast two-hybrid screen for proteins that interact with actin depolymerization factor (ADF; Okada et al., 1999), known as cofilin in yeast. Both Xenopus and yeast AIP1 have been shown to enhance the filament disassembling activity of ADF/ cofilin, to cap actin filaments, and to restrict cofilin localization to cortical actin patches (Rodal et al., 1999). These studies predicted that WDR1 would be involved in the highly regulated process of actin polymerization and depolymerization termed actin dynamics (Chen et al., 2000).

In this study we identified the site(s) of WDR1 expression in normal and noise-damaged chick cochlea and examined colocalization of WDR1 protein with F-actin and $\mathrm{ADF} /$ cofilin. In the normal chick cochlea, WDR 1 was expressed in hair cells, homogene cells, and cuboidal cells. Furthermore, F-actin and ADF/cofilin were present at high levels in these cells. Following acoustic overstimulation, WDR 1 mRNA and protein were detected in supporting cells in the region where hair cells were damaged. WDR 1 was also upregulated in the tegmentum vasculosum, whereas expression in homogene cells and cuboidal cells was unaffected. These results are consistent with the known role of yeast and Xenopus AIP1 in actin dynamics and are the first step in understanding the role of WDR1 in the maintenance and repair of the inner ear.

\section{MATERIALS AND METHODS}

\section{Experimental groups and noise conditions}

The experimental groups and noise conditions were described previously (Adler et al., 1999). Hatchling chicks (7-10-day-old Cornish Cross Broiler variety obtained from Hoover's Hatchery, Rudd, IA) were divided into three groups. Nonexposed, age-matched animals served as a control group. Intense sound (octave band with a center frequency of $1.5 \mathrm{kHz}$ presented at $118 \mathrm{~dB} \mathrm{SPL}$, relative to $20 \mu \mathrm{Pa}$ ) was applied for 5-6 hours. These parameters for acoustic overstimulation were chosen because they lead to a lesion involving loss of hair cells but not supporting cells and are therefore compatible with regeneration (Cotanche et al., 1991; Raphael, 1993). Animals in the acoustic trauma group were euthanized immediately after removal from the noise by decapitation, and those in the recovery group were allowed to recover for 2 days after noise before euthanasia. This research has been reviewed by the University Committee on the Use and Care of Animals. For embryos, fertilized White Leghorn eggs (Bilbie Hatcher-

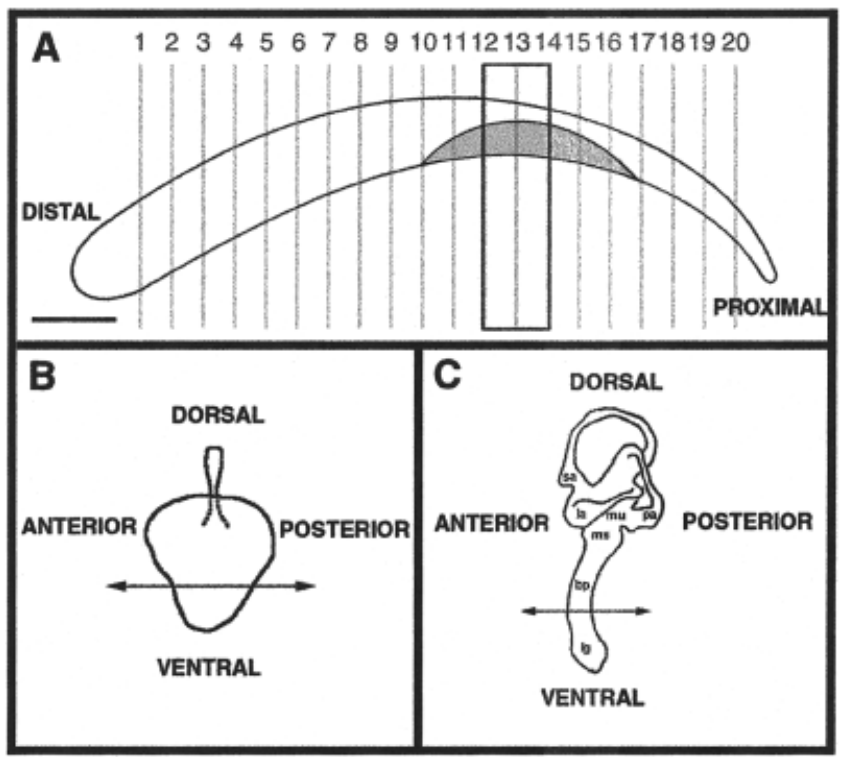

Fig. 1. Schematic representations of cochlear structures and sections. A: Schematic diagram of the chick basilar papilla at P7. Numbers indicate the approximate positions of 20 serial sections, at 160- $\mu \mathrm{m}$ intervals, that were collected on each slide. The shaded area denotes the crescent-shaped lesion caused by acoustic overstimulation. B: Schematic of the developing otocyst at E4. The endolymphatic duct has emerged from the dorsal aspect of the otocyst, while the cochlear duct is beginning to elongate from the ventral region. The line indicates the plane of section through the emerging cochlear duct used in Figure 5A. C: Schematic of the inner ear at E7. By E7, the inner ear structures are morphologically distinct. The three semicircular canals have differentiated from the dorsal otocyst, and the cochlear duct has extended ventromedially. The line indicates the plane of section through the cochlear duct used in Figure 5B. Scale bar $=0.5 \mathrm{~mm}$ in A.

ies, Ann Arbor, MI) were incubated for the designated times. Embryos were staged (Hamburger and Hamilton, 1951) up to embryonic day 5 (E5). Older embryos were referred to by embryonic days.

\section{Frozen sections}

Immediately after chicks were decapitated, the inner ears were removed and fixed overnight with $4 \%$ paraformaldehyde in phosphate-buffered saline (PBS), $\mathrm{pH}$ 7.5. The cochleae were further dissected to remove surrounding bony tissue, leaving the tegmentum vasculosum attached. Cochleae were then cryoprotected in $30 \%$ sucrose and embedded in OCT. Sections from each cochlea were collected onto 16 SuperFrost slides (VWR, Pittsburgh, PA). Slides were used alternately to mount sections, so that each glass slide contained approximately 20 cross sections (10 $\mu \mathrm{m}$ thick) covering the entire chick cochlea (Fig. 1A). By this method, we could observe the whole cochlea in one slide under the same condition and also could compare adjacent sections using different probes or antibodies. Sections were cut transverse to the long axis of the papilla and stored in a dessicator at $-80^{\circ} \mathrm{C}$.

\section{In vitro transcription}

Digoxigenin (DIG)-labeled antisense and sense RNA probes were generated from a $1.5-\mathrm{kb}$ partial chick WDR1 cDNA (KH279) (Adler et al., 1999) that included both the 
coding region and the $3^{\prime}$ UTR. Antisense riboprobes were made using T7 RNA polymerase from an EcoRI linearized template, and sense riboprobes were made using T3 RNA polymerase from an XhoI linearized template. In vitro transcription was performed with a DIG RNA Labeling Kit (Roche Diagnostics, Indianapolis, IN) from $1 \mu \mathrm{g}$ of linearized plasmid DNA. The cRNA product was resuspended in $100 \mu \mathrm{l}$ DEPC water, and the probe was stored at $-20^{\circ} \mathrm{C}$. The corresponding sense probe was included in each experiment as a control and yielded little hybridization signal.

\section{In situ hybridization}

Hybridization conditions, washes, and detection procedures were carried out as described by Jensen and Wallace (1997). DIG-labeled RNA probes were diluted (250$1,000 \mathrm{ng} / \mathrm{ml}$ ) in hybridization buffer (50\% formamide, $10 \%$ dextran sulfate, $1 \mathrm{mg} / \mathrm{ml}$ yeast RNA, $1 \times$ Denhardt's solution, $200 \mathrm{mM} \mathrm{NaCl}, 5 \mathrm{mM} \mathrm{NaH} \mathrm{PO}_{4}, 5 \mathrm{mM} \mathrm{Na}_{2} \mathrm{HPO}_{4}, 5$ $\mathrm{mM}$ EDTA, and $10 \mathrm{mM}$ Tris, $\mathrm{pH}$ 7.5) and denatured for 10 minutes at $70^{\circ} \mathrm{C}$. Sections were hybridized overnight at $65^{\circ} \mathrm{C}$ in a humidified box. The slides were washed twice in $50 \%$ formamide, $1 \times \mathrm{SSC}, 0.1 \%$ Tween-20 at $65^{\circ} \mathrm{C}$ for 30 minutes followed by 2 washes in MABT (100 mM maleic acid, $150 \mathrm{mM} \mathrm{NaCl}$, pH 7.5, 0.1\% Tween-20) for $30 \mathrm{~min}-$ utes at room temperature. Sections were blocked for 2-4 hours at room temperature in MABT containing $20 \%$ sheep serum (Sigma, St. Louis, MO) and 2\% blocking solution (Roche Diagnostics), which was then replaced with blocking solution containing a 1:1,500 dilution of alkaline-phosphatase-conjugated Fab fragments of sheep anti-DIG antibodies (Roche Diagnostics).

Slides were incubated overnight at $4^{\circ} \mathrm{C}$ in a humidified box and washed five times in MABT for 20 minutes at room temperature and then twice in staining buffer $(100$ $\mathrm{mM} \mathrm{NaCl}, 50 \mathrm{mM} \mathrm{MgCl}_{2}, 100 \mathrm{mM}$ Tris, $\mathrm{pH} 9.5$, and $0.1 \%$ Tween-20). Next, slides were incubated overnight in staining buffer containing NBT/BCIP stock solution (Roche Diagnostics) and 10\% polyvinyl alcohol (BDH, Toronto, Ontario, Canada) (De Block and Debrouwer, 1993) at room temperature until enough color reaction was developed. The slides were washed in $20 \mathrm{mM}$ EDTA in PBS, and mounted in Crystal Mount (Biomeda, Foster City, CA). Tissue sections from both in situ hybridization and immunostaining with various antibodies (see below) were examined using a Leica DMRB epifluorescence microscope (Eaton, PA), and photographed using Ektachrome 160T slide film (Eastman Kodak, Rochester, NY). All findings were examined in a minimum of five different cochleae, and the images shown are typical representative ones.

\section{Generation of anti-WDR1 antibodies}

Polyclonal antibodies were generated against a synthetic peptide, MPYEIKKVFASL, coupled to bovine serum albumin (Princeton Biomolecules, Columbus, OH). This sequence is present at the amino termini of both mouse and human WDR1 proteins (amino acids 1-12), and the identical sequence occurs in chick WDR1 (residues 3-14). Two rabbits were pre-bled and then received an injection of the peptide every other week until the tenth week. These animals were bled 5 times, beginning at 8 weeks after the initial peptide injection and every 2 weeks thereafter. The reactivity and specificity of the immune sera to the synthetic peptides were confirmed by analyzing the ability of dilutions of sera to detect the peptides using enzyme-linked immunosorbent assays (ELISAs). Brains and livers from seven chicks (14 days of age) were homogenized and bound overnight to wells in a 96-well Falcon 3912 Microtest III Flexible Assay plate. Dilutions of anti-WDR1 antisera were added to the wells and subsequently incubated with goat anti-rabbit antibodies conjugated with alkaline phosphatase. The absorbance of p-nitrophenyl phosphate (pNPP) was measured at 405 $\mathrm{nm}$. The optimal concentrations of anti-WDR1 antisera were represented by 1:1,000 and 1:10,000 dilutions.

We confirmed the specificity of the anti-WDR1 antibodies by Western blot analysis. Chick cochlear proteins were separated by sodium dodecyl sulfate-polyacrylamide gel electrophoresis (SDS-PAGE) (Laemmli, 1970). For immunoblotting, proteins were electrophoretically transferred from the SDS-polyacrylamide gel to PVDF Western blotting membranes (Roche Diagnostics) as described (Towbin et al., 1979). The membrane was treated with $5 \%$ skim milk in PBT (PBS, pH 7.5, with 0.1\% Tween-20) for 1 hour, incubated with the primary antibody; anti-WDR1 (1:1500) and anti-XAIP (1:800), and then treated with horseradish peroxidase (HRP)-conjugated secondary antibody. The membrane was thoroughly washed with PBT after each immunoreaction and finally incubated with a chemiluminescence agent (ECL; Amersham Pharmacia Biotech, Buckinghampshire, UK). A single band of approximately $60 \mathrm{kDa}$ was observed with the anti-WDR1 polyclonal antibody (data not shown).

\section{Immunocytochemistry}

Immunocytochemistry was performed on serial sections (Fig. 1). By using adjacent frozen sections for in situ hybridization and immunocytochemistry, we could compare both mRNA expression and protein distribution. Two different antisera were used for immunolocalization of WDR1: antibodies raised to chick WDR1 (see above) and anti-XAIP1 antibodies to the Xenopus homologue of WDR1 (XAIP1) (Okada et al., 1999). Following washes in PBS, the tissue sections were permeabilized by incubating the slides in $0.1 \%$ Triton $\mathrm{X}-100$ for 10 minutes and then incubating them overnight with the primary antibodies, either a 1:300 dilution of rabbit anti-WDR1 antisera or a 1:600 dilution of rabbit anti-XAIP1 antisera, both at $4^{\circ} \mathrm{C}$. The immunocytochemistry findings with anti-XAIP1 antibodies were identical to those with anti-WDR1 antibodies. Anti-ADF antisera, provided by Dr. James Bamburg (Morgan et al., 1993), was used at a dilution of 1:400. Slides were then incubated in 1:50 dilution of rhodamine (TRITC)-conjugated goat anti-rabbit antibodies (Jackson ImmunoResearch, West Grove, PA) and 1:500 dilutions of fluorescein (FITC)-conjugated phalloidin (Molecular Probes, Eugene, OR) for 20 minutes. After PBS washes, the slides were mounted with CrystalMount (Biomeda) and photographed as described for in situ hybridization.

\section{RESULTS}

\section{WDR1 is expressed in cochlear hair cells}

AIP1 is known to bind to and enhance the rate of cleavage of actin filaments in yeast (Rodal et al., 1999) and frogs (Okada et al., 1999). This finding suggested that WDR1, the chick and mammalian homologue of AIP1, might be required for maintenance of the actin cytoskeleton in cells such as auditory hair cells that have high 

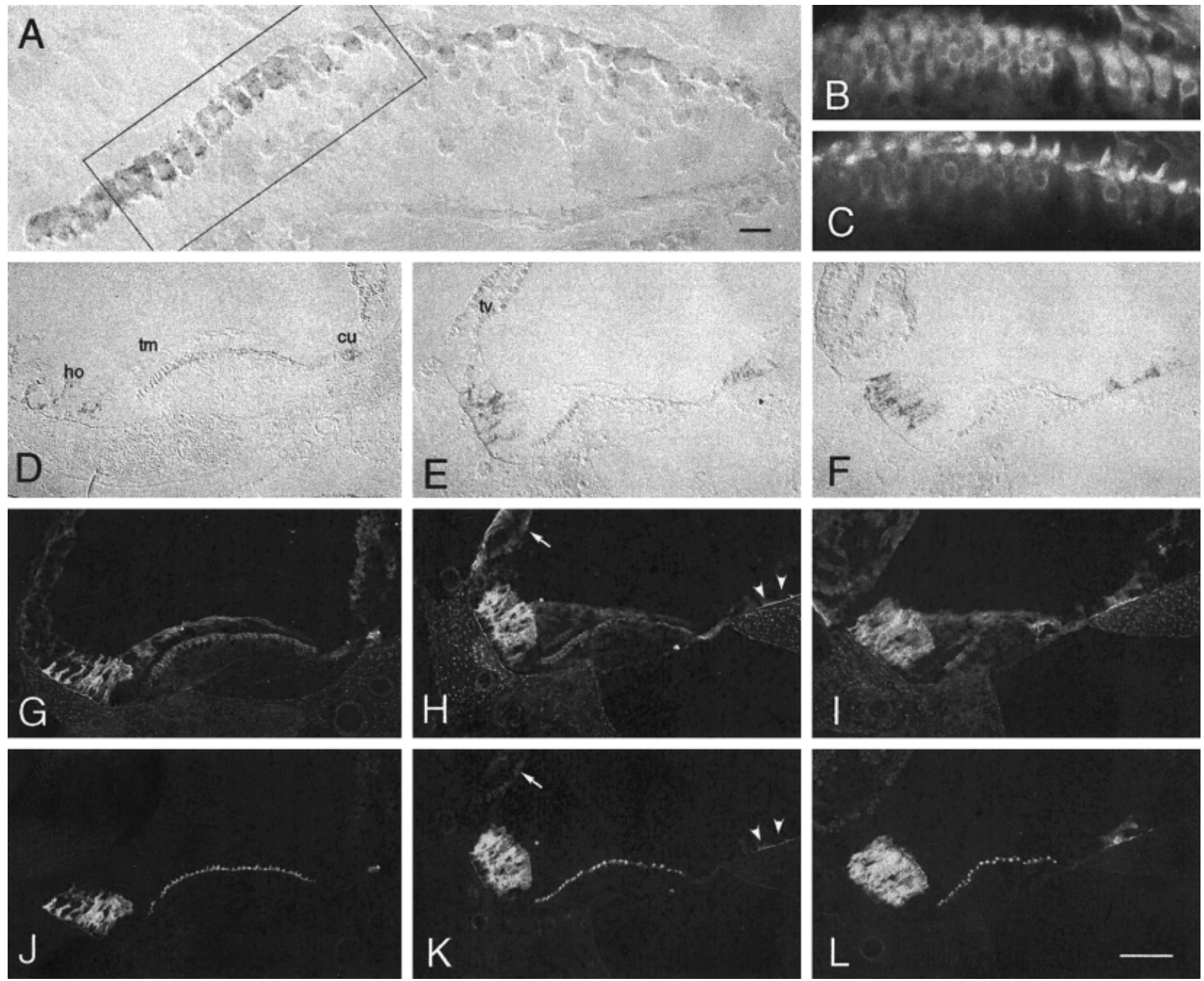

Fig. 2. WDR1 expression in normal cochlea. A: WDR1 expression in hair cells. In situ hybridization with an anti-sense riboprobe for WDR1 on mid-cochlear sections. Enclosed in the box is the area of most intense WDR1 expression, also shown in B and C. Note the gradient of expression from the tall hair cells at the superior edge of the cochlea (left) to the short hair cells at the inferior edge (right). B: Immunocytochemical localization of WDR1 immunoreactivity in the basilar papilla in the boxed area of panel A. C: Localization of F-actin in hair cells in same section as shown in B. D-L: Sections from the distal (D,G,J), middle (E,H,K), and proximal (F,I,L) portions of the basilar papilla represent regions that are about 500,2,000, and 3,000 $\mu \mathrm{m}$ from the distal end, respectively. Sections in D-F were hybridized with a WDR1 cRNA probe for clone KH 279. The data obtained with two different WDR1 probes, KH279 and KH274, were identical. Furthermore, sense probes for both KH279 and KH 274 showed no signal above the background (data not shown). G and J, H and K, I and L are the same sections, double-labeled with anti-WDR1 antibody $(\mathrm{G}, \mathrm{H}, \mathrm{I})$ and FITC-conjugated phalloidin to visualize F-actin (J,K,L). Normal basilar papillae that were stained with either anti-WDR1 or antiXAip antibodies showed the same pattern. Abbreviations: ho, homogene cell; cu, cuboidal cell; tm, tectorial membrane; tv, tegmentum vasculosum. Arrows denote tegmentum vasculosum, and arrowheads denote cuboidal cells. The immunostaining of tectorial membrane (and the hyaline cells) was also seen in the absence of anti-WDR antibodies and represents nonspecific staining. Scale bars $=10 \mu \mathrm{m}$ in A (applies to A-C), $100 \mu \mathrm{m}$ in L (applies to D-L). levels of actin. To test this prediction, we examined serial sections of the normal chick basilar papilla (see schematic in Fig. 1A) for WDR1 mRNA and WDR1 immunoreactivity. We visualized F-actin filaments with FITC-coupled phalloidin (Fig. 2). In situ hybridization analysis (Fig. 2A) revealed high levels of WDR $1 \mathrm{mRNA}$ in hair cells, but not supporting cells. We also detected a gradient of WDR1 mRNA levels from the superior to the inferior edge of the basilar papilla. Within the same cross section, the tall hair cells (Fig. 2A) always contained more WDR1 mRNA than the short hair cells (Fig. 2A). Hair cells also showed intense WDR1 immunoreactivity (Fig. 2B) and a high level of phalloidin-labeled F-actin (Fig. 2C).

\section{$W D R 1$ is expressed in cells containing high levels of $\mathrm{F}$-actin}

To determine whether or not high WDR1 expression correlated with high actin content in other regions of the cochlea, we examined sections extending from the proximal end to the distal end of the basilar papilla (Fig. 1A). 
The WDR1 gene was highly expressed in several different types of cells in the avian cochlea. In addition to hair cells, in situ hybridization analysis detected high levels of WDR1 mRNA in two distinct cell types: homogene cells and cuboidal cells (Fig. 2D-F). These cells contain large amounts of actin filaments and are believed to anchor the superior and inferior edges of the tectorial membrane, respectively. Consistent with the in situ hybridization results, WDR1 immunostaining (Fig. 2G,H) was observed in these cells. We compared the distribution of WDR1 protein (Fig. 2G-I) and F-actin (Fig. 2J-L) in the same sections by double immunocytochemistry. We observed WDR1 immunoreactivity and F-actin staining in hair cells, homogene cells, and cuboidal cells (arrowheads in Fig. 2H,K). Low levels of immunoreactivity were present in the tegmentum vasculosum (arrows in Fig. $2 \mathrm{H}, \mathrm{K}$ ) and auditory ganglion cell bodies (data not shown). These results indicated that WDR1 is highly expressed in cells with high levels of F-actin. WDR1 was not detected in supporting cells, either by in situ hybridization or by immunocytochemistry.

Representative cross sections from the distal to the proximal ends of the chick cochlea (see schematic diagram in Fig. 1A) were collected on a single slide and hybridized simultaneously; therefore, we could compare the intensity of the in situ hybridization signals at different regions along the cochlea. The pattern of WDR1 expression was similar in each serial section, although the level of expression appeared to increase from the distal end (Fig. 2D) to the proximal end (Fig. 2F), suggesting a gradient of expression along the tonotopic axis of the cochlea (Smith and Takasaka, 1971; Takasaka and Smith, 1971).

A gradient of WDR1 expression was apparent in both homogene and cuboidal cells (Fig. 2D-F). Because the number of homogene cells and cuboidal cells increased from the distal to the proximal end as determined by the number of nuclei in these regions, this increased expression may be due in part to a greater number of homogene and cuboidal cells. The pattern of actin distribution, as demonstrated by the fluorescein (FITC)-conjugated phalloidin staining, also showed the same increasing gradient in homogene and cuboidal cells (Fig. 2J-L). In some sections, anti-WDR1 immunoreactivity in the cuboidal cell was mainly located at the basal domain of the cells, where they attached to the inferior fibrocartilagenous plate (Fig. $2, \mathrm{H}$, arrowheads). This finding is corroborated by $\mathrm{F}$-actin distribution (Fig. 2K, arrowheads). Low levels of WDR1 mRNA could also be found in the tegmentum vasculosum, the chick equivalent of the mammalian stria vascularis (Fig. 2E, tv) and the auditory ganglion (not shown). This lower level of WDR1 expression in tegmentum vasculosum correlated with weaker immunostaining for WDR1 (Fig. $2 \mathrm{H}$, arrow) and staining for F-actin (Fig. 2K, arrow).

\section{WDR1 mRNA and protein in noise-damaged chick cochlea}

We previously demonstrated by Northern blot analysis increased expression of WDR 1 immediately following a 4-6-hour period of acoustic overstimulation, with a return to normal levels 2 days following the noise exposure (Adler et al., 1999). To determine whether or not this increase was due to increased expression of WDR 1 in regions where it is normally expressed, or was due to expression in cells in which WDR1 mRNA was previously undetectable, we performed in situ hybridization studies on the normal chick basilar papilla (Fig. 3A), and on the basilar papilla immediately following (Fig. 3B) and 2 days after the noise exposure (Fig. 3C). We observed induction of WDR1 mRNA in supporting cells in the lesioned area of the basilar papilla immediately after noise overstimulation (Fig. 3B). (The lesioned area is indicated by the shaded area in the schematic diagram, Fig. 1A). WDR1 mRNA was still present at the damaged area 2 days later (Fig. $3 \mathrm{C}$, arrowheads). WDR1 immunoreactivity was measured on adjacent sections and was detected in the damaged area 2 days after noise. This was an appropriate length of time for the translation of WDR1 mRNA and/or the accumulation of WDR1 protein (Fig. 3F). The increase in WDR 1 mRNA and protein in supporting cells was confined to the lesion; no expression was seen in supporting cells in the adjacent area proximal or distal to the lesion (data not shown). WDR1 mRNA was barely detectable by in situ hybridization in the tegmentum vasculosum of control animals (Fig. 3G) but increased significantly immediately after noise (Fig. 3H), with a return to normal low levels 2 days later (Fig. 3I). The WDR1 immunoreactivity in noiseexposed animals (Fig. 3K) was similar to the control (Fig. 3J) and appeared to be even higher 2 days later (Fig. 3L).

\section{Colocalization of WDR1 and ADF/cofilin}

Because AIP1 is known to interact with cofilin in yeast (Rodal et al., 1999) and with the similar protein ADF in frogs (Okada et al., 1999), we examined WDR1 (vertebrate AIP1) and ADF/cofilin immunoreactivity in adjacent sections of the normal and acoustically damaged chick cochlea. Immunoreactivity for both WDR1 (Fig. 4A) and ADF/cofilin (Fig. 4E) was detected in hair cells, but not supporting cells, in the normal chick basilar papilla. Following noise damage, we observed WDR1 (Fig. 4B) and ADF/cofilin (Fig. 4F) immunoreactivity and actin labeling (Fig. 4G) in supporting cells in the lesion (shaded area in Fig. 1A), but not in sections distal or proximal to the lesion.

\section{WDR1 expression in developing chick cochlea}

The chick basilar papilla is capable of regenerating hair cells following acoustic or ototoxic damage. To determine whether or not the ectopic expression of WDR1 in supporting cells was recapitulating developmental expression of this gene in supporting cells, we examined where and when the WDR1 is expressed during development. In situ hybridization was performed on sections of chick embryos at four different stages between E4 and E16. WDR1 mRNA was first detected at E4 in two rather broad and indistinct regions of the otocyst: a dorsomedial region that will develop into the vestibular organs, and a ventrolateral region that will develop into the cochlear duct (Brigande et al., 2000a,b) (Fig. 5A). Examination of the early basilar papilla at E7 (Fig. 5B) revealed a high level of WDR 1 expression in two distinctive areas, the presumptive homogene cells and cuboidal cells. At E12 (Fig. 5C), we detected additional low level expression in hair cells and the tegmentum vasculosum. By E16 (Fig. 5D), the overall pattern of WDR1 expression was similar to that seen in the mature normal chick cochlea at posthatching day 7, except for a conspicuous cuboidal cell expression. We did not detect WDR1 mRNA in supporting cells at any developmental stage. Thus, the ectopic expression of WDR 1 in supporting cells was a response of these cells to 

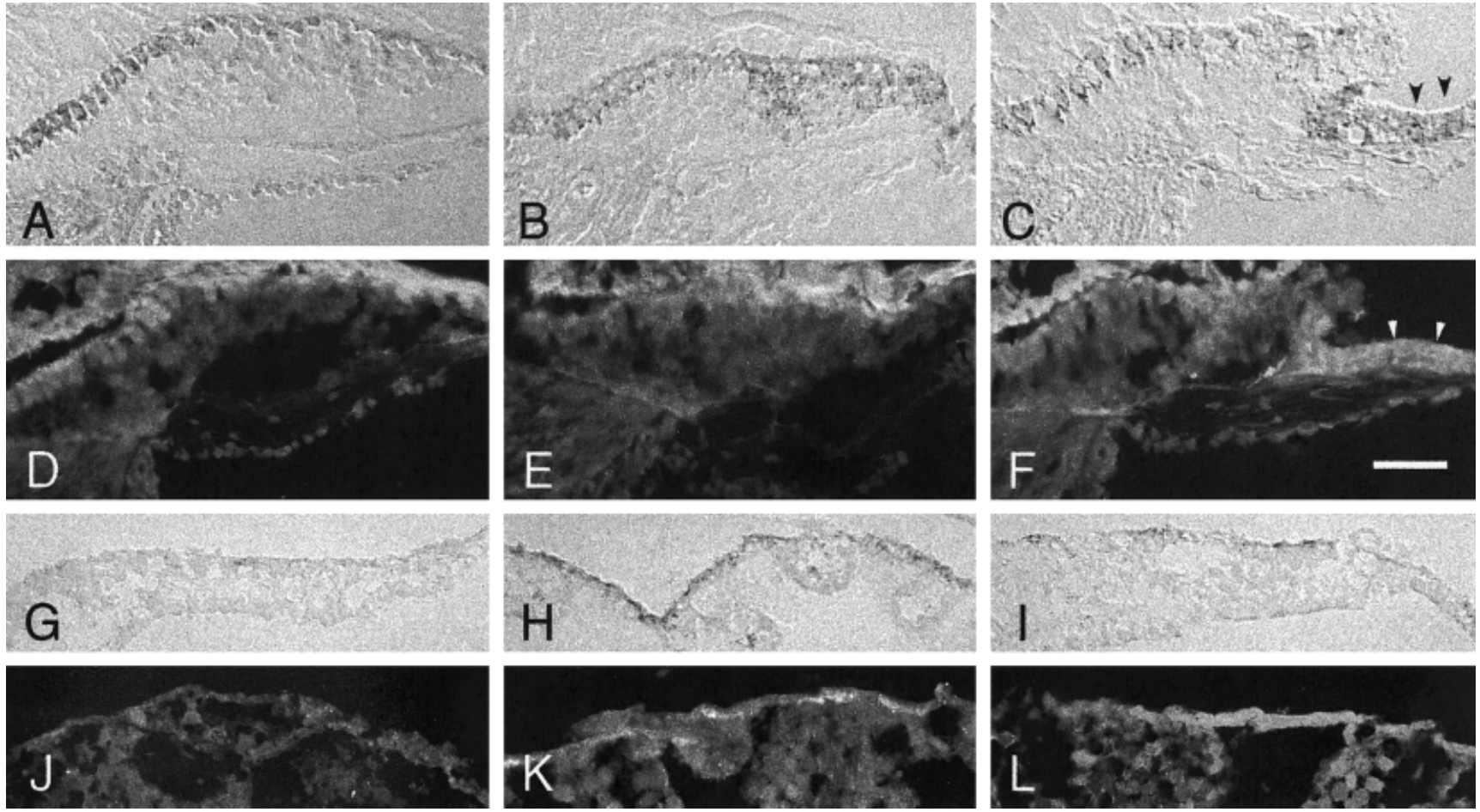

Fig. 3. Induction of WDR1 mRNA and protein expression in noisedamaged chick cochlea. A-F: WDR1 expression in normal (A,D), noise-damaged $(\mathrm{B}, \mathrm{E})$, and regenerating $(\mathrm{C}, \mathrm{F})$ basilar papilla. Sections through the basilar papilla in the region of greatest damage due to acoustic trauma (rectangle in schematic basilar papilla of Fig. 1A) were hybridized with a WDR 1 probe to detect WDR 1 mRNA (A-C), or, were immunostained with anti-XAip antibody to detect WDR1 protein (D-F). In the normal basilar papilla WDR 1 mRNA and protein are detected in hair cells (A,D). After the noise, WDR1 mRNA is present also in supporting cells (B). It takes 2 more days for the WDR1 protein to be detected in the tissue (F). G-L: WDR1 expression increases in the tegmentum vasculosum after noise damage to the chick cochlea. WDR 1 is expressed at low levels in the tegmentum vasculosum in control cochlea $(\mathrm{G})$, but expression increased immediately after noise (H) and returned to normal 2 days later (I). Protein levels are low in the normal tegmentum vesculosum $(\mathrm{J})$, slightly increased after trauma $(\mathrm{K})$, and become prominent 2 days later (L), when message levels decreases (I). Scale bar $=50 \mu \mathrm{m}$ in F (applies to A-L). the noise trauma but does not reflect reexpression of a developmental program for this gene.

\section{DISCUSSION \\ WDR1 in hair cells of the normal basilar papilla}

Actin-interacting protein 1 (AIP1) was isolated in two different types of yeast two-hybrid screens. One screen identified proteins that interact with yeast actin (Amberg et al., 1995); the second identified proteins that interact with Xenopus actin-depolymerizing factor (ADF) (Okada et al., 1999). Further studies demonstrated that AIP1 interacts with $\mathrm{ADF} /$ cofilin to increase the rate of actin depolymerization and that AIP1 is a capping protein for actin filaments (Rodal et al., 1999). Thus, in lower eukaryotes, AIP1 is involved in actin filament turnover, or actin dynamics (Chen et al., 2000). We therefore assume that WDR1, the chick and mammalian homologue of AIP1 (Adler et al., 1999), is also involved in actin dynamics in vertebrates.

WDR1 expression in hair cells, which contain high levels of both actin and ADF/cofilin, is consistent with the proposed role of WDR1 in actin dynamics. Three different kinds of actin filament structures have been found at the apex of chick hair cells: 1 ) actin filaments in stereocilia, 2) actin filaments forming the cuticular plate; and 3) the circumferential belt attached to the cytoplasmic aspect of the zonula adherens (DeRosier and Tilney, 1989; Tilney et al., 1989; Drenckhahn et al., 1991). Electron microscopic studies will be necessary to determine the exact subcellular localization of WDR1 protein. Actin is also present in supporting cells as a terminal web and in microvilli, although we could not detect WDR1 mRNA or protein in supporting cells in the normal cochlea.

The functional significance of the gradient of WDR1 expression and F-actin distribution, from the distal to proximal ends of the cochlea, is not apparent. Gradients of voltage-gated calcium channels have been observed between tall and short hair cells in the chick basilar papilla (Martinez-Dunst et al., 1997). Tall hair cells are presynaptic to the majority of afferent neurons in the cochlea and are analogous to mammalian inner hair cells. Short hair cells are the postsynaptic targets of efferent neurons and are analagous to mammalian outer hair cells. Tall hair cells with many afferent contacts expressed a high number of calcium channels, whereas the abneurally located short hair cells with little or no afferent contacts expressed a low number. Conversely, short hair cells preferentially expressed an inactivating potassium channel (Murrow and Fuchs, 1990). Thus, the higher expression of WDR 1 in tall hair cells may relate to the type of innerva- 

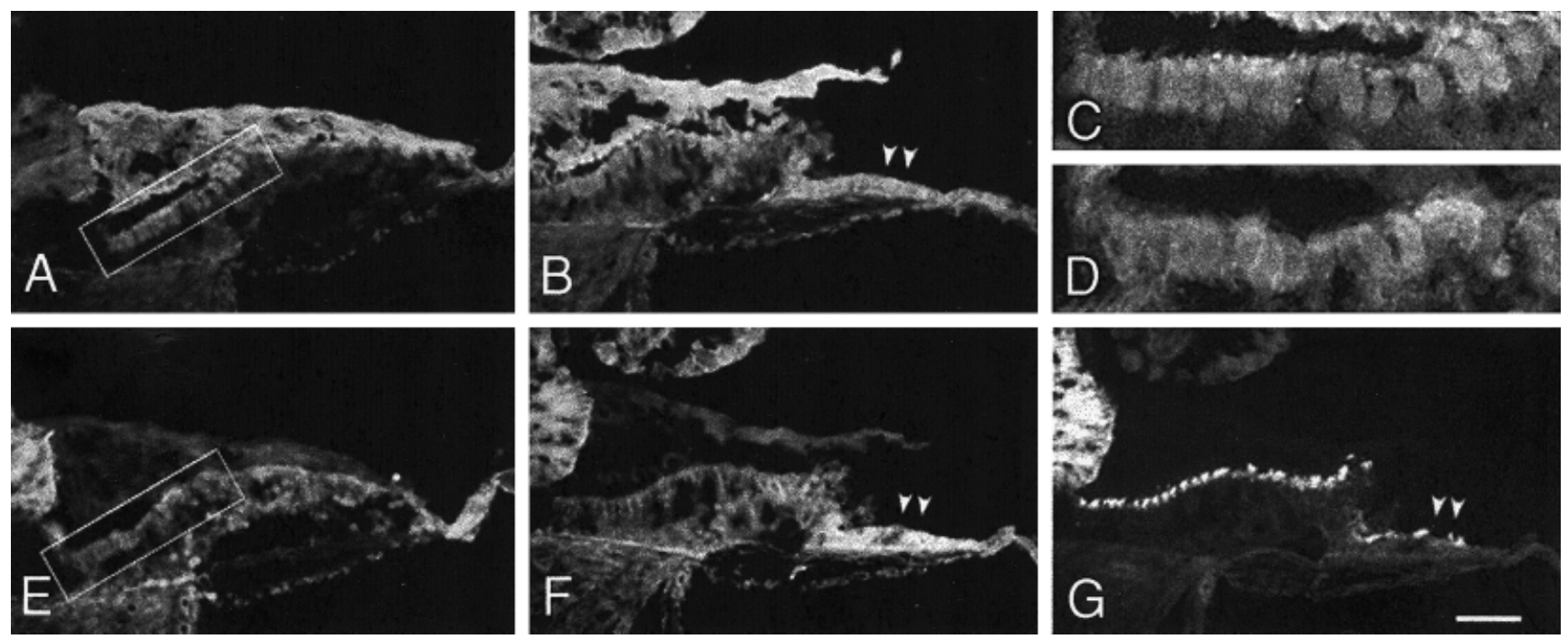

Fig. 4. Epifluorescence micrographs of cryosections of the basilar papilla before noise exposure (A,E,C,D) and 2 days after the exposure $(\mathrm{B}, \mathrm{F}, \mathrm{G})$, showing colocalization of WDR1 $(\mathrm{A}-\mathrm{C})$ and $\mathrm{ADF} / \mathrm{cofilin}(\mathrm{D}-\mathrm{F})$ in normal and noise-damage basilar papilla. $\mathrm{A}$ and $\mathrm{E}$ are adjacent $10-\mu \mathrm{m}$ sections from normal cochlea; $\mathrm{B}$ and $\mathrm{F}$ are adjacent $10-\mu \mathrm{m}$ sections of the noise-exposed cochlea. A: WDR1 is present in hc of the basilar papilla. B: Two days after the noise trauma, WDR1 is immunolocalized in the lesioned area of short hair cells. C-D: Higher magnification of rectangular area in $\mathrm{A}$ and $\mathrm{E}$, demonstrating colocal-

ization of WDR1 and ADF/cofilin immunoreactivity in hair cells of the basilar papilla. E,F: Similar sections to A and B, stained for ADF/ cofilin. ADF/cofilin protein colocalized with WDR1 not only in normal cochlea (compare A with $\mathrm{E}$ and $\mathrm{C}$ with $\mathrm{D}$ ) but also in the damaged area (arrowheads in B and F). G: FITC-phalloidin staining of section F. High levels of F-actin are observed at the lesion (arrowheads), corresponding to increased staining for WDR1 and ADF/cofilin (in B and F). Scale bar $=50 \mu \mathrm{m}$ in $\mathrm{G}$ (applies to A,B,E-G), $20 \mu \mathrm{m}$ in $\mathrm{G}$ (applies to $\mathrm{C}, \mathrm{D})$.

tion. Alternative splicing of calcium-activated potassium channels along the tonotopic axis of the chick basilar papilla may be involved in auditory tuning of hair cells (Navaratnam et al., 1997).

\section{WDR1 expression in homogene cells}

WDR1 mRNA and protein are present in homogene cells, which anchor the superior edge of the tectorial membrane. WDR1 protein colocalized with actin filaments and ADF/cofilin. Homogene cells, along with supporting cells, have been considered to secrete the tectorial membrane during development (Cohen and Fermin, 1985; Shiel and Cotanche, 1990). However, there is some controversy about the contribution of homogene cells in synthesizing the tectorial membrane. $\beta$-Tectorin, a major component of the tectorial membrane, is detected in supporting cells, clear cells, and cuboidal cells, but not in homogene cells (Goodyear et al., 1996; Heller et al., 1998). We now report that WDR 1 is expressed at a much earlier stage (E4) than the period when the tectorial membrane is synthesized (E7). WDR1 expression continues after hatching when tectorial membrane secretion is no longer active (Cohen and Fermin, 1985). Thus, the expression of WDR1 in homogene cells is most likely related to functions other than tectorial membrane synthesis.

Heller and colleagues (1998) identified a gene highly expressed in homogene cells that encodes a protein they named homogenin. Homogenin is $75 \%$ identical to human gelsolin, a calcium-regulated protein that binds to the fast-growing end of actin polymers and severs actin filaments (Heller et al., 1998). Gelsolin, one of the actinmodulating proteins found in all organisms from lower eukaryotes to mammals, is functionally similar to a mam- malian plasma protein of similar size (Stossel, 1984; Schafer and Cooper, 1995). Heller et al. (1998) proposed that the high level of homogenin and filamentous actin in homogene cells is required for the cytoskeleton to counter the forces on the tectorial membrane that occur during acoustical stimulation. Our finding of WDR 1 expression in homogene cells firmly supports the hypothesis that both WDR1 and homogenin (gelsolin) are involved in actin turnover, perhaps to provide mechanical support to withstand the vibrations of the tectorial membrane. Interestingly, however, their expression patterns are different. Homogenin was concentrated at the apical domain of homogene cells (Heller et al., 1998), whereas WDR1 immunoreactivity was more intense at the basal domain.

However, this finding does not necessarily exclude the possibility that WDR 1 functions in generating the tectorial membrane. In the developing cochlea of the rat, gelsolin was localized in cells of Kolliker's organ, which are involved in the secretion of the tectorial membrane (Rabie et al., 1988). Noise overstimulation may not show an increase of WDR1 expression in homogene cells. Excessive noise probably disrupts the tectorial membrane's attachment to the tip of hair cells and supporting cells. Thus, the shearing force from the vibration of the basilar papilla could no longer affect the homogene cells.

\section{Acoustic overstimulation induces WDR1 expression in supporting cells}

The reorganization of the actin cytoskeleton during cellular response to various stress conditions is well known (Kalnins et al., 1995; Jacinto et al., 2001). Actin is known to be one of the most dynamically changing proteins of the cytoskeleton in the sensory epithelium after noise insult 

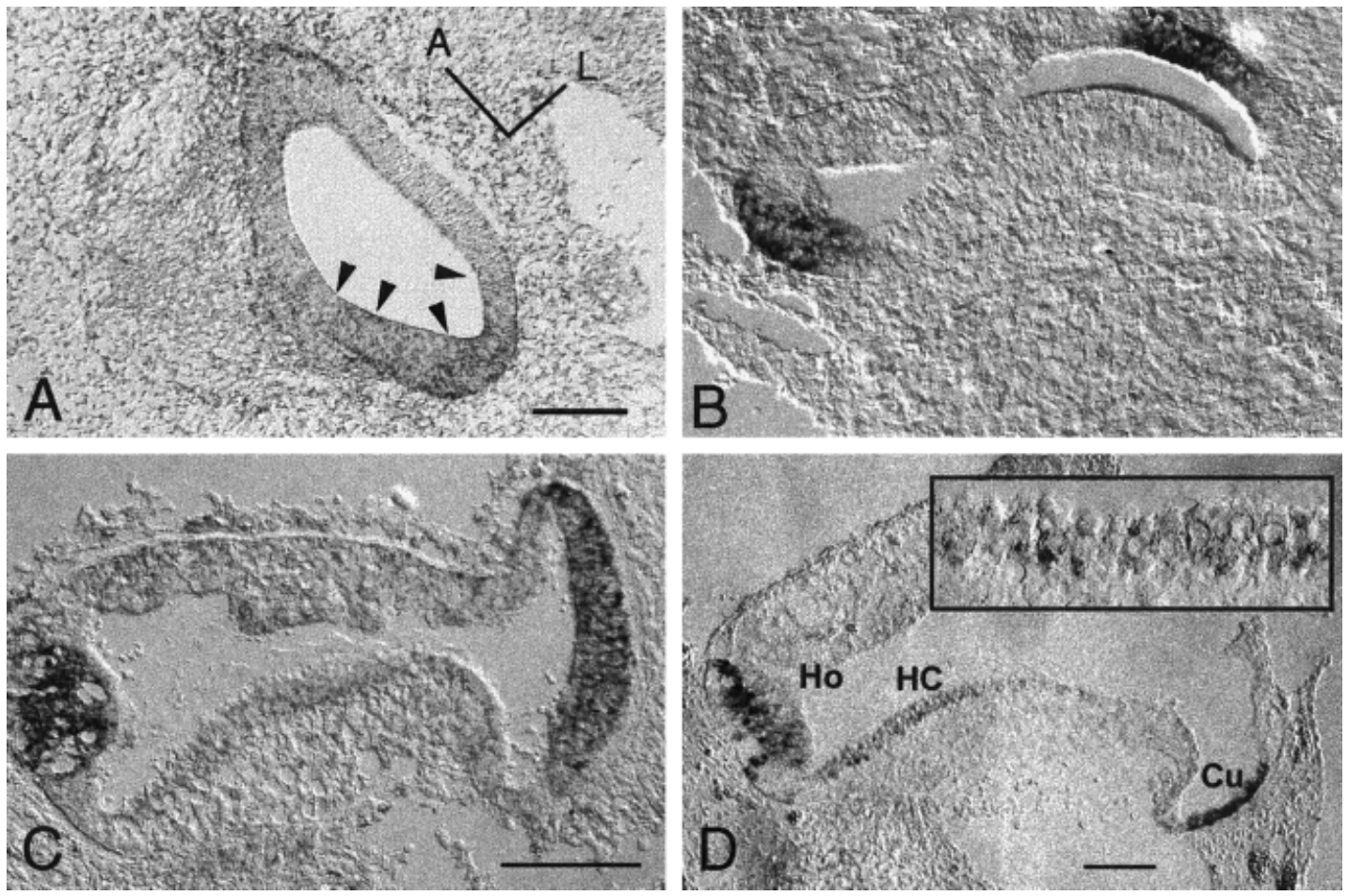

Fig. 5. Developmental expression of WDR1. In situ hybridization was performed on sections through the otocyst (A) and developing cochlear duct (B-D) with an antisense probe for WDR1. A: Horizontal section of E4 otocyst (see line in Fig. 1B, E4), taken from the budding area of pars inferior where the future cochlea will develop. Anterior and posterior (arrowheads) domains of WDR1 expression are shown. B: Section of the developing cochlear duct from E7 (as indicated by the line in Fig. 1C, E7). Two distinctive areas for the presumptive homogene and cuboidal cells are positively stained. C: Cross section of E12 in a similar orientation to that in B. WDR1 expression is seen in hair cells in the basilar papilla and in the tegmentum vasculosum. Robust

(Tilney et al., 1982; Avinash et al., 1993; Lee and Cotanche, 1995). Similarly, in Dictyostelium, cofilin plays a pivotal role, in concert with AIP1, in the reorganization of actin architecture into bundles that contract in a myosinII-independent manner in response to hyperosmotic stress (Aizawa et al., 1999).

One of the more important functions of actin in the auditory epithelium is to maintain a continuous epithelial barrier between the endolymphatic and perilymphatic fluids by providing mechanical strength to the intercellular junctions. Maintaining the epithelial barrier is crucial to the hair cell mechano-electrical transduction (Forge, 1985; Raphael and Altschuler, 1991a). The cells in the basilar papilla separate endolymph from perilymph and must withstand movement during sound stimulation (Smith and Takasaka, 1971; Takasaka and Smith, 1971). The tight junctions (zonula occludens) in the apical intercellular space provide the seal that prevents the diffusion of electrolytes and other molecules between the fluid compartments, whereas the adherens junctions (zonula adherens) provide adhesive forces that maintain cell coupling under mechanical stress (Bazzoni et al., 1999; Dejana et al., 1999).

In the auditory epithelium, the actin belt is especially prominent in heterotypic junctions (hair cell-supporting

staining is seen in homogene cells (on the left) and the presumptive cuboidal cell area (on the right). D: Cross section of dissected E16 cochlea. The section was as shown in Figure 1C, P7. Expression of WDR 1 found in hair cells. The rectangle shows a higher magnification of the hair cell area. The overall pattern of expression is similar to the mature cochlea, except for a wider area of WDR 1 expression in the cuboidal cells at E16. Homogene and cuboidal cells are also stained. Abbreviations: Ho, homogene cell; $\mathrm{Cu}$, cuboidal cell; $\mathrm{HC}$, hair cells. Orientation bar: A, anterior; L, lateral. Scale bars $=100 \mu \mathrm{m}$ in A, 50 $\mu \mathrm{m}$ in $\mathrm{C}$ (applies to B,C), $50 \mu \mathrm{m}$ in D.

cell junctions; Smith and Takasaka, 1971; Takasaka and Smith, 1971), suggesting that supporting cells play a major role in maintaining the surface tension of the reticular lamina. During the response to acoustic trauma, supporting cells may play a key role in maintaining the surface tension and barrier system when supporting cells create a scar to replace a damaged or lost hair cell (Cotanche and Dopyera, 1990; Cotanche et al., 1991; Raphael, 1993). If the normal barrier of adherens junctions between hair cells and supporting cells has been disrupted by extensive sound overstimulation, immediate restoration of the junction is required (Poje et al., 1995). Thus, the immediate increase of WDR1 within the supporting cells might be part of a regulatory process to enhance the rate of actin turnover and the generation of F-actin filaments for junctional contacts.

The moderate noise level used in this study (118 dB SPL at $1.5 \mathrm{kHz}$ for $5-6$ hours) induced partial hair cell damage and supporting cell expansion. In a moderately damaged basilar papilla (115-117 dB for 4-6 hours), the apical surfaces of the hair cells constrict, and the surrounding supporting cells expand their apical surfaces to maintain the continuity of the epithelial surface (Raphael, 1993; Cotanche et al., 1995). In comparison, a severe acoustic trauma with massive hair cell loss precluded complete 
structural regeneration of the basilar papilla (Cotanche et al., 1995; Cotanche, 1997), suggesting that the survival of supporting cells and an intact reticular lamina are essential for a complete recovery and/or regeneration of sensory epithelium following acoustic overstimulation. We observed increased immunoreactivity for both WDR1 and ADF/cofilin, along with increased actin filament synthesis, in supporting cells after noise damage. These increases were restricted to the crescent-shaped, noise-induced lesion of the basilar papilla. The undamaged areas proximal or distal to the lesion showed no changes in WDR1 and ADF/cofilin immunoreactivity. The increased levels of all three proteins within supporting cells in the lesion suggest an active role for actin rearrangement during damage and/or the regeneration process of chick cochlea and may reflect the expansion or migration of the supporting cells to replace the lost hair cells.

Supporting cells also play important roles in the regenerative process. They are the major contributors to inner ear repair, either by reentering the cell cycle and proliferating (Ryals and Rubel, 1988; Hashino et al., 1991; Raphael and Altschuler, 1992; Raphael, 1993; Stone and Cotanche, 1994) or by converting directly into hair cells without mitosis (Adler and Raphael, 1996; Roberson et al., 1996; Adler et al., 1997). Supporting cells are also considered to be a source of tectorial membrane during development (Shiel and Cotanche, 1990) and regeneration (for reviews, see Saunders et al., 1996; Cotanche, 1999).

High intensity noise, such as 24-hour exposure to 123 dB SPL, produces severe damage to the auditory epithelium in birds by destroying both hair cells and supporting cells. A flattened layer of epithelial cells replaces degenerated short hair cells with distinctly different surface characteristics from the adjacent supporting cells. Migration of hyaline cells into the basilar papilla may contribute to the cellular replacement (Cotanche et al., 1995). It would be interesting to determine whether or not the WDR 1 expression pattern is different if the chick cochlea is subjected to severe noise that does not allow regeneration of hair cells, but would instead produce irreversible scars. This experiment might determine whether or not WDR 1 expression is related to hair cell regeneration or to the damage process. It would also be interesting to determine whether or not such changes in WDR1 expression occur in mammals following noise overstimulation where regeneration does not occur.

\section{WDR1 expression in the tegmentum vasculosum}

WDR1 expression in the tegmentum vasculosum increased after noise overstimulation. Significant morphologic changes were found within the tegmentum vasculosum of quail sacrificed on days $0-4$, but the tegmentum vasculosum returned to its normal condition after 4 days (Ryals et al., 1995). Expression of otokeratin, a component of the intermediate filament network, was seen in cells of the tegmentum vasculosum, suggesting a role of the tegmentum vasculosum as a mechanical barrier that withstands pressure changes (Heller et al., 1998). The significance of upregulation of WDR 1 in the tegmentum may be interpreted as the restoration of the mechanical barrier by accelerating actin turnover and thus reorganizing the actin cytoskeleton. Alternatively, WDR1 expression may be related to the maintenance of the intact tegmentum vasculosum that is necessary to restore the capacity to secrete potassium and maintain the endocochlear potential (Poje et al., 1995).

\section{Developmental changes of WDR1 expression in chick inner ear}

Regenerating systems often reexpress developmentally regulated genes. For example, in regenerating muscle fibers the appearance of embryonic isoforms of musclespecific proteins precedes the adult isoforms. We therefore asked whether or not the expression of WDR1 in supporting cells after noise trauma recapitulated the developmental program. We did not observe expression of WDR1 in supporting cells in the chick cochlea at those stages of development that we examined, which suggests that the expression of WDR1 following noise is not related to its developmental program.

The pattern of WDR1 expression at E4 defines two broad areas that will soon undergo considerable morphologic changes. The high levels of WDR1 mRNA in these regions may reflect an increase in actin dynamics and cell motility in these rapidly expanding regions. Additional experiments at early time points with markers such as bone morphogenetic protein 4 (BMP4) that define the sensory epithelium will be necessary to address this important question. At E7, WDR1 appears to define the presumptive homogene and cuboidal cells. Thus, the WDR1 gene could be a useful marker for both. The only other marker for either of these cell types is the homogenin gene, which encodes a protein similar to gelsolin (Heller et al., 1998). Gelsolin can also cleave actin filaments, in a calcium-dependent fashion.

\section{CONCLUSIONS}

We demonstrated colocalization of WDR1 and F-actin in hair cells, homogene cells, and cuboidal cells of the basilar papilla. These cells are rich in actin filaments. The data supported a role for WDR1 in actin dynamics in the cells of the inner ear. The expression of WDR 1 in precursors of these cell types during development provided an early marker to distinguish these cells in the developing cochlea. Furthermore, the increased expression of WDR 1 in supporting cells following noise damage suggested that WDR1 may play an important role in regeneration of the auditory epithelium following acoustic trauma. Further studies in both birds and mammals will be required to ascertain the exact role of WDR 1 in this process.

\section{ACKNOWLEDGMENTS}

We thank Dr. Hiroshi Abe, Chiba University, Japan, for providing antibodies to XAIP1, the Xenopus AIP1 protein, and Dr. James Bamburg, Colorado State University, for providing the anti-ADF antibodies. M.I.L. was the recipient of NIH grant DC02492, and Y.R. was the recipient of NIH grant DC01634.

\section{LITERATURE CITED}

Adler HA, Komeda M, Raphael Y. 1997. Further evidence for supporting cell conversion in the damaged avian basilar papilla. Int J Dev. Neurosci 15:375-385.

Adler HJ, Raphael YR. 1996. New hair cells arise from supporting cell conversion in the acoustically damaged chick inner ear. Neurosci Lett 205:17-20. 
Adler HJ, Poje CP, Saunders JC. 1993. Recovery of auditory function and structure in the chick after two intense pure tone exposures. Hear Res 71:214-224.

Adler HJ, Winnicki RS, Gong T-WL, Lomax MI. 1999. A gene upregulated in the acoustically damaged chick basilar papilla encodes a novel WD40 repeat protein. Genomics 56:59-69.

Aizawa H, Katadae M, Maruya M, Sameshima M, Murakami-Murofushi K, Yahara I. 1999. Hyperosmotic stress-induced reorganization of actin bundles in Dictyostelium cells over-expressing cofilin. Genes Cells 4:311-324.

Amberg DC, Basart E, Botstein D. 1995. Defining protein interactions with yeast actin in vivo. Nat Struct Biol 2:28-35.

Avinash GB, Nuttall AL, Raphael Y. 1993. 3-D analysis of F-actin in stereocilia of cochlear hair cells after loud noise exposure. Hear Res 67:139-146.

Bazzoni G, Martinez Estrada O, Dejana E. 1999. Molecular structure and functional role of vascular tight junctions. Trends Cardiovasc Med 9:147-152.

Brigande JV, Iten LE, Fekete DM. 2000a. A fate map of chick otic cup closure reveals lineage boundaries in the dorsal otocyst. Dev Biol 227:256-270.

Brigande JV, Kiernan AE, Gao X, Iten LE, Fekete DM. 2000b. Molecular genetics of pattern formation in the inner ear: do compartment boundaries play a role? Proc Natl Acad Sci USA 97:11700-11706.

Chen H, Bernstein BW, Bamburg JR. 2000. Regulating actin-filament dynamics in vivo. Trends Biochem Sci 25:19-23.

Cohen GM, Fermin CD. 1985. Development of the embryonic chick's tectorial membrane. Hear Res 18:29-39.

Corwin JT, Cotanche DA. 1988. Regeneration of sensory hair cells after acoustic trauma. Science 240:1771-1774.

Cotanche DA. 1987a. Regeneration of hair cell stereociliary bundles in the chick cochlea following severe acoustic trauma. Hear Res 20:181-196.

Cotanche DA. 1987b. Regeneration of the tectorial membrane in the chick cochlea following severe acoustic trauma. Hear Res 30:197-206.

Cotanche DA. 1992. Video-enhanced DIC images of the noise-damaged and regenerated chick tectorial membrane. Exp Neurol 115:23-26.

Cotanche DA. 1997. Hair cell regeneration in the avian cochlea. Ann Otol Rhinol Laryngol Suppl 168:9-15.

Cotanche DA. 1999. Structural recovery from sound and aminoglycoside damage in the avian cochlea. Audiol Neurootol 4:271-285.

Cotanche DA, Dopyera CE. 1990. Hair cell and supporting cell response to acoustic trauma in the chick cochlea. Hear Res 46:29-40.

Cotanche DA, Petrell A, Picard DA. 1991. Structural reorganization of hair cells and supporting cells during noise damage, recovery and regeneration in the chick cochlea. Ciba Found Symp 160:131-142; discussion 142-150.

Cotanche DA, Messana EP, Ofsie MS. 1995. Migration of hyaline cells into the chick basilar papilla during severe noise damage. Hear Res 91:148159.

De Block M, Debrouwer D. 1993. RNA-RNA in situ hybridization using digoxigenin-labeled probes: the use of high-molecular-weight polyvinyl alcohol in the alkaline phosphatase indoxyl-nitroblue tetrazolium reaction. Anal Biochem 215:86-89.

Dejana E, Bazzoni G, Lampugnani MG. 1999. The role of endothelial cell-to-cell junctions in vascular morphogenesis. Thromb Haemost 82 : $755-761$.

DeRosier DJ, Tilney LG. 1989. The structure of the cuticular plate, an in vivo actin gel. J Cell Biol 109:2853-2867.

Drenckhahn D, Engel K, Hofer D, Merte C, Tilney L, Tilney M. 1991. Three different actin filament assemblies occur in every hair cell: each contains a specific actin crosslinking protein. J Cell Biol 112:641-651.

Forge A. 1985. Outer hair cell loss and supporting cell expansion following chronic gentamicin treatment. Hear Res 19:171-182.

Gong T-WL, Hegeman AD, Shin JJ, Adler HJ, Raphael Y, Lomax MI. 1996. Identification of genes expressed after noise exposure in the chick basilar papilla. Hear Res 96:20-32.

Goodyear R, Killick R, Legan PK, Richardson GP. 1996. Distribution of beta-tectorin mRNA in the early posthatch and developing avian inner ear. Hear Res 96:167-178.

Hamburger V, Hamilton HL. 1951. A series of normal stages in the development of the chick embryo. J Morphol 88:49-92.

Hashino E, Tanaka Y, Sokabe M. 1991. Hair cell damage and recovery following chronic application of kanamycin in the chick cochlea. Hear Res 52:356-368.
Hawkins JE Jr, Johnsson LG. 1976. Patterns of sensorineural degeneration in human ears exposed to noise. In: Henderson D, Hamernik RP, Dosanjh DS, Hirsh IJ and Silverman SR, editors. Effects of noise on hearing. New York: Raven Press. p 91-110.

Heller S, Sheane CA, Javed Z, Hudspeth AJ. 1998. Molecular markers for cell types of the inner ear and candidate genes for hearing disorders. Proc Natl Acad Sci USA 95:11400-11405.

Jacinto A, Martinez-Arias A, Martin P. 2001. Mechanisms of epithelial fusion and repair. Nat Cell Biol 3:E117-123.

Jensen AM, Wallace VA. 1997. Expression of Sonic hedgehog and its putative role as a precursor cell mitogen in the developing mouse retina. Development 124:363-371.

Kalnins VI, Sandig M, Hergott GJ, Nagai H. 1995. Microfilament organization and wound repair in retinal pigment epithelium. Biochem Cell Biol 73:709-722.

Laemmli UK. 1970. Cleavage of structural proteins during the assembly of the head of bacteriophage T4. Nature 227:680-685.

Lee KH, Cotanche DA. 1995. Detection of beta-actin mRNA by RT-PCR in normal and regenerating chicken cochleae. Hear Res 87:9-15.

Martinez-Dunst C, Michaels RL, Fuchs PA. 1997. Release sites and calcium channels in hair cells of the chick's cochlea. J Neurosci 17:91339144.

McFadden EA, Saunders JC. 1989. Recovery of auditory function following intense sound exposure in the neonatal chick. Hear Res 41:205-215.

Morgan TE, Lockerbie RO, Minamide LS, Browning MD, Bamburg JR. 1993. Isolation and characterization of a regulated form of actin depolymerizing factor. J Cell Biol 122:623-633.

Murrow BW, Fuchs PA. 1990. Preferential expression of transient potassium current (IA) by 'short' hair cells of the chick's cochlea. Proc R Soc Lond B Biol Sci 242:189-195.

Navaratnam DS, Bell TJ, Tu TD, Cohen EL, Oberholtzer JC. 1997. Differential distribution of $\mathrm{Ca} 2+$-activated $\mathrm{K}+$ channel splice variants among hair cells along the tonotopic axis of the chick cochlea. Neuron 19:1077-1085

Niemiec AJ, Raphael Y, Moody DB. 1994. Return of auditory function following structural regeneration after acoustic trauma: behavioral measures from quail. Hear Res 79:1-16

Okada K, Obinata T, Abe H. 1999. XAIP1: a Xenopus homologue of yeast actin interacting protein 1 (AIP1), which induces disassembly of actin filaments cooperatively with ADF/cofilin family proteins. J Cell Sci 112:1553-1565.

Poje CP, Sewell DA, Saunders JC. 1995. The effects of exposure to intense sound on the DC endocochlear potential in the chick. Hear Res 82:197204

Pugliano FA, Wilcox TO, Rossiter J, Saunders JC. 1993. Recovery of auditory structure and function in neonatal chicks exposed to intense sound for 8 days. Neurosci Lett 151:214-218.

Rabie A, Ferraz C, Clavel MC, Legrand C. 1988. Gelsolin immunoreactivity and development of the tectorial membrane in the cochlea of normal and hypothyroid rats. Cell Tissue Res 254:241-245.

Raphael Y. 1993. Reorganization of the chick basilar papilla after acoustic trauma. J Comp Neurol 330:521-532.

Raphael Y, Altschuler RA. 1991a. Reorganization of cytoskeletal and junctional proteins during cochlear hair cell degeneration. Cell Motil Cytoskel 18:215-227.

Raphael Y, Altschuler RA. 1991b. Scar formation after drug-induced cochlear insult. Hear Res 51:173-183.

Raphael Y, Altschuler RA. 1992. Early microfilament reorganization in injured auditory epithelia. Exp Neurol 115:32-36.

Roberson DW, Kreig CS, Rubel EW. 1996. Light microscopic evidence that direct transdifferentiation gives rise to new hair cells in regenerating avian auditory epithelium. Auditory Neurosci 2:195-205.

Rodal AA, Tetreault JW, Lappalainen P, Drubin DG, Amberg DC. 1999. Aip1p interacts with cofilin to disassemble actin filaments. J Cell Biol 145:1251-1264.

Ryals BM, Rubel EW. 1988. Hair cell regeneration after acoustic trauma in adult Coturnix quail. Science 240:1774-1776.

Ryals BM, Stalford MD, Lambert PR, Westbrook EW. 1995. Recovery of noise-induced changes in the dark cells of the quail tegmentum vasculosum. Hear Res 83:51-61.

Saunders JC, Adler HJ, Pugliano FA. 1992. The structural and functional aspects of hair cell regeneration in the chick as a result of exposure to intense sound. Exp Neurol 115:13-17. 
Saunders JC, Doan DE, Cohen YE, Adler HJ, Poje CP. 1996. Recent observations on the recovery of structure and function in the sounddamaged chick ear. In: Salvi RJ, Henderson D, Fiorino F, Colletti V, editors. Auditory system plasticity and regeneration. Buffalo, NY: Thieme Medical Publishers, Inc. p 62-83.

Schafer DA, Cooper JA. 1995. Control of actin assembly at filament ends. Annu Rev Cell Dev Biol 11:497-518.

Shiel MJ, Cotanche DA. 1990. SEM analysis of the developing tectorial membrane in the chick cochlea. Hear Res 47:147-157.

Smith CA, Takasaka T. 1971. Auditory receptor organs of reptiles, birds, and mammals. Contrib Sensory Physiol 5:129-178.

Stone JS, Cotanche DA. 1994. Identification of the timing of S phase and the patterns of cell proliferation during hair cell regeneration in the chick cochlea. J Comp Neurol 341:50-67.
Stossel TP. 1984. Contribution of actin to the structure of the cytoplasmic matrix. J Cell Biol 99:15s-21s.

Takasaka T, Smith CA. 1971. The structure and innervation of the pigeon's basilar papilla. J Ultrast Res 35:20-65.

Tilney LG, Saunders JC, Egelman E, DeRosier DJ. 1982. Changes in the organization of actin filaments in the stereocilia of noise-damaged lizard cochleae. Hear Res 7:181-197.

Tilney MS, Tilney LG, Stephens RE, Merte C, Drenckhahn D, Cotanche DA, Bretscher A. 1989. Preliminary biochemical characterization of the stereocilia and cuticular plate of hair cells of the chick cochlea. J Cell Biol 109:1711-1723.

Towbin H, Staehelin T, Gordon J. 1979. Electrophoretic transfer of proteins from polyacrylamide gels to nitrocellulose sheets: procedure and some applications. Proc Natl Acad Sci USA 76:4350-4354. 